\title{
ANÁLISE DE SOFRIMENTO MENTAL DE TRABALHADORES QUE ATUAM NO SETOR DE SEGURANÇA PRIVADA
}

\section{ANALYSIS OF MENTAL SUFFERING OF WORKERS ACTING IN THE PRIVATE SECURITY SECTOR}

\author{
Ana Cláudia Fagundes \\ Universidade Federal de Uberlândia (UFU) \\ anacfpsicologia@yahoo.com.br \\ Rafael Lemes de Aquino \\ Universidade Federal de Uberlândia (UFU) \\ rafael.aquino@ufu.br \\ Paulo Cezar Mendes \\ Universidade Federal de Uberlândia (UFU) \\ pcmendes@ig.ufu.br
}

\begin{abstract}
RESUMO
Objetivo: Investigar a prevalência de adoecimentos mentais dos trabalhadores que atuam no seguimento de segurança privada. Método: Pesquisa de estudo quantitativo, descritivo e bibliográfico. Estudo realizado em uma empresa situada em Uberlândia, Minas Gerais. Fizeram parte do estudo 281 trabalhadores do gênero masculino e feminino, que trabalham nos turnos diurno e noturno, com escala de trabalho $12 / 36 \mathrm{~h}$, cujos cargos de vigilante, porteiro, recepcionista, segurança pessoal, atendente de monitoramento eletrônico e demais administrativos, que tenham apresentado ASO (Atestado de Saúde Ocupacional) e suas respectivas classificações no CID-10 (Classificação Internacional de Doenças) categoria $F$ (letra que identifica os transtornos), no período de janeiro/2012 à dezembro/2015. Resultados: Mediante tais evidências, concluiu-se que este seguimento de trabalho é carente de investigações e com os achados do estudo é considerada uma área geradora de patologias relacionadas ao adoecimento mental e agravantes de cunho físico.
\end{abstract}

Palavras-chave: Saúde do trabalhador. Segurança privada. Saúde mental.

\begin{abstract}
Objective: To investigate the prevalence of mental illness of workers who work in private security follow-up. Method: Quantitative, descriptive and bibliographic study research. Study conducted at a company located in Uberlândia, Minas Gerais. The study included 281 male and female workers, working day and night shifts with a 12/36 work scale, whose positions as watchman, porter, receptionist, personal security, electronic monitoring attendant and other presented ASO (Occupational Health Certificate) and their respective classifications in the ICD-10 (International Classification of Diseases) category F (letter that identifies the disorders), from January / 2012 to December / 2015. Results: Based on these evidences, it was concluded that this work follow-up is a great enhancer of pathologies related to mental illness and physical aggravation.
\end{abstract}

Keywords: Worker's health. Private security. Mental health.

Recebido em: 27/03/2019

Aceito para publicação em: 11/07/2019 


\section{INTRODUÇÃO}

No Brasil, a insegurança da população acabou possibilitando o surgimento de novas empresas de segurança privada. O grande crescimento dos serviços de vigilância, além das questões de violência, se dá também devido à limitação dos serviços públicos mediante as grandes demandas das novas formas de organização que foram surgindo nos espaços coletivos (FENAVIST, 2012).

Neste contexto, o setor de segurança privada atua com o intuito de preservar os espaços de propriedades particulares (residências, empresas e etc.), empregando recursos humanos (vigilante, porteiro, segurança pessoal), implementando equipamentos (alarmes, câmeras de vigilância, circuito fechado de TV, portas com sensores sonoros), e instalações (cercas elétricas, muros, portas giratórias). Cabe destacar que os profissionais deste seguimento, além de prestarem serviços na "casa do cliente" deparam-se, cotidianamente, com uma grande diversidade de ambientes de trabalho. Assim, quer sejam eles vigilantes, porteiros, recepcionistas, têm por obrigação funcional a que adaptar as exigências advindas da empresa de origem (a que detém o vínculo contratual, e pagador do seu salário) como também adaptar ao ambiente e exigências do contratante onde foi escalado para atuar.

O trabalho está presente na vida do homem ao longo da história da humanidade, e sua influência sobre a saúde dos trabalhadores é conhecida desde a antiguidade. Historicamente, homem e trabalho se interligam de diferentes maneiras, conforme a sociedade e o período ao qual nos referimos, de modo que os significados sociais atribuídos ao trabalho sempre têm influenciado o contexto vivenciado pelo homem (CAVALHEIRO; TOLFO, 2011).

Portanto, essa pesquisa é fruto de um estudo e parte de uma dissertação de mestrado, que teve como objetivo investigar, no período de 2012 a 2015, a incidência de adoecimento mental dos trabalhadores de uma empresa que atuam no seguimento de segurança privada na cidade de Uberlândia/MG. Propõe-se também, adensar reflexões teóricas sobre a temática, descrever os transtornos mentais e comportamentais identificados no período proposto, correlacionar os atestados ao número de dias que o trabalhador esteve ausente, com os principais transtornos apresentados.

Devido a sua importância como fonte de subsistência para si e para outros seres humanos e para a formação subjetiva do homem, versando como um elemento central em sua vida, o trabalho deveria ser visto como algo bom, positivo e desejável. Entretanto, ao longo da história, o trabalho para a maioria da humanidade tem representado dor, adoecimento e morte, fruto das diferentes formas de exploração a que os homens têm sido submetidos ao longo dos séculos, principalmente após expansão do modelo capitalista, na segunda metade do século XX, com o aumento das exigências laborativas ao trabalhador, levando a sérias implicações sobre a sua saúde (BRAGA; CARVALHO; BINDER, 2010, p.1588; CAVALHEIRO; TOLFO, 2011, p. 246).

Como vimos, estes autores contribuem com o conceitualização teórica reflexiva sobre o mundo do trabalho, reforçando assim a importância de se ter um olhar diferenciado para estas classes trabalhadoras contemporâneas. As questões que envolvem a psicodinâmica do trabalho tornam-se pontos fundamentais de preocupação para os que lidam com a saúde pública e privada, sobretudo quando se sabe que, a separação entre mente e corpo é apenas uma questão didática, e que o conceito de saúde vai muito além do que a mera ausência sintomática de doenças.

E diante de inúmeros desafios, se estabelecem reflexões da atual realidade do mundo trabalho e suas lacunas entre saúde-doença, em um cenário contemporâneo bastante intenso e desafiador. O estudo sobre "Análise de sofrimento mental de trabalhadores que atuam no setor de segurança privada", revela-se os 58 tipos de transtornos relacionados à saúde mental, tais como: transtorno pânico, episódio depressivo leve, ansiedade generalizada, episódio depressivo grave, dentre outros.

Este estudo corrobora-se com reflexão e construção de dados concretos onde evidenciam a necessidade de um trabalho diferenciado para este seguimento de profissionais. Ademais, constata que o trabalho, por sua vez, pode ser visto como fonte de saúde ou também de adoecimento.

\section{MÉTODO}

Trata-se de uma pesquisa de estudo quantitativo, descritivo e bibliográfico. Elaborou-se no período de 2012 a 2015, para efeito de coleta e análise de dados, presente nos relatórios disponibilizados pelo 
Serviço Especializado em Engenharia de Segurança e Medicina do Trabalho (SESMT) da empresa. Não foi realizada nenhum tipo de abordagem aos trabalhadores e sim análises de relatórios disponibilizados pelo local do estudo.

O estudo foi realizado em uma empresa que atua no setor de segurança privada, prestando serviços de segurança patrimonial, segurança eletrônica, segurança documental e monitoramento de alarmes, com sede no município de Uberlândia/MG. Foram analisados 389 atestados de saúde ocupacional (ASO) e suas respectivas Classificações Internacional de Doenças e comportamentais (CID-10).

E seguramente, no contexto de trabalho dos profissionais que atuam no setor de segurança privada, a pesquisa descritiva busca evidenciar, através da coleta e análise de dados presentes nos relatórios disponibilizados pelo da empresa, o teor das análises e dos estudos realizados, evidenciando consequentemente os resultados.

A pesquisa descritiva exige do investigador uma série de informações sobre o que deseja pesquisar. Esse tipo de estudo pretende descrever os fatos e fenômenos de determinada realidade (TRIVIÑOS, 1987). Nas análises e interpretações dos resultados, as amostragens foram tabuladas em planilhas eletrônicas (Excel) e resumidas por meio de estatística descritiva e apresentadas em forma de gráficos e tabelas.

Outrossim, foi realizada uma pesquisa bibliográfica pertinente à abrangência da temática, buscando uma sustentação teórica e metodológica. Por outro lado, não foi feito nenhum tipo de abordagem aos participantes da pesquisa descritos nos relatórios disponibilizados pelo setor de Serviço.

O estudo foi realizado em uma empresa de segurança privada, cuja sede está localizada no município de Uberlândia/MG, abrangendo uma área de atuação nos estados de Minas Gerais, Goiás, Mato Grosso, Mato Grosso do Sul, São Paulo e Paraná. A mesma, opera a mais de 15 anos na prestação de serviços de segurança patrimonial, segurança eletrônica, segurança documental e monitoramento de alarmes e sistemas.

A amostra do estudo foram de 281 trabalhadores, do gênero masculino e feminino, que trabalham nos turnos diurno e noturno, com escala de trabalho 12/36, cujo cargos de vigilante, porteiro, recepcionista, segurança pessoal, atendente de monitoramento eletrônico e demais administrativos, que tenham apresentado algum tipo de atestado de Saúde ocupacional, no período de janeiro/2012 à dezembro/2015.

Foram feitos levantamento e análise dos dados de saúde presentes nos relatórios do setor e foram identificados os registros dos ASO e suas respectivas classificações no CID-10, cuja análise realizada no período de janeiro de 2012 à dezembro de 2015. Em um segundo momento, acesso ao cadastro dos profissionais que apresentaram os atestados de saúde ocupacional, junto ao setor de Recursos Humanos da empresa, para análise e coleta de dados tais como período de admissão e ou desligamento, idade, gênero, estado civil, cargo, data admissão, data desligamento, posto de trabalho, escala.

Os dados obtidos foram compilados em planilha eletrônica (Excel), para posterior amostra estatística através da confecção de quadros demonstrativos, tabelas e gráficos, a fim de evidenciar análises dos dados e precisão dos resultados obtidos. Dados contidos na planilha: código do funcionário, data admissão, data do desligamento, início do afastamento, término do afastamento, quantidade dias ausente, quantidade dias de auxílio concedido pela empresa, CID apresentado.

Sendo assim, esta fase demanda foco e dedicação por parte do pesquisador, pois, tal instrumento viabilizará a precisão dos resultados e consequentemente os objetivos a serem alcançados com a pesquisa. Já quanto aos aspectos éticos e para efeito de análise e proteção dos direitos dos seres humanos, do Comitê de Ética em Pesquisa da Universidade Federal de Uberlândia/MG (número do CAAE: 64777216.8.0000.515).

\section{REFERENCIAL TEÓRICO}

\section{Breve histórico sobre as conquistas no âmbito da saúde do trabalhador brasileiro}

No Brasil, ao final dos anos 1970, uma nova concepção denominada "Saúde do Trabalhador" rompeu com velhos modelos de compreensão dos modos de produzir doenças (MENDES, DIAS, 1991; 
WAISSMANN, CASTRO, 1996), e tanto a Medicina Social Latino-Americana, como o Modelo Operário Italiano (MINAYO-GOMES, LACAZ, 2005; THEDIM-COSTA, 1997) tiveram reflexos na estruturação das ações de Vigilância em Saúde do Trabalhador (VISAT) no país.

A VISAT surge com o intuito de promover e proteger a saúde do trabalhador, evitando situações e condições geradoras de sofrimento, de doenças profissionais e de acidentes de trabalho. Para alcançar tais objetivos, devem incorporar sistemática e criteriosa avaliação e planejamento da demanda e do alcance das ações desenvolvidas (MACHADO, 1996; VILELA, 2003).

Em 1980, foi criado o Departamento Intersindical de Estudos e Pesquisas de Saúde e dos Ambientes de Trabalho (DIESAT). Já em 1988 a criação do Sistema Único de Saúde (SUS) e, ainda, da Lei Orgânica de Saúde (BRASIL, 1988; BRASIL, 1990) é que o setor de saúde do Estado passou a coordenar as ações de Saúde do Trabalhador, intervindo nos espaços de trabalho.

Reconhece-se que o homem sempre esteve na condição de transformar o seu meio, atuando em suas condições doadoras de capacidades físicas e intelectuais. Sendo assim, Foucaut, (2006) acrescenta que o interesse principal da vida e do trabalho é que os mesmos permitem tornar-se diferente do que você era no início do seu processo.

Segundo Lacaz (1992; 1996) e Minayo-Gomez e Lacaz (2005), a prática acumulada nos Programas de Saúde do Trabalhador (PST), embasada na participação dos trabalhadores (em alguns casos, na sua gestão, controle e avaliação); na integralidade das ações de assistência e vigilância; e na universalidade de acesso, orientou a forma de atenção à saúde dos trabalhadores como atribuição do Sistema de Saúde, mesmo antes de existir na atual configuração como SUS.

A partir de 1998, com a publicação da Norma Operacional e Saúde do Trabalhador, por meio da Portaria n. 3.908/GM, de 30 de outubro de 1998, foram estabelecidos os procedimentos para orientar e instrumentalizar as ações e serviços no âmbito do SUS. Os princípios básicos de ação estabelecidos pela portaria são os mesmos do SUS: universalidade, equidade e integralidade; planejamento e execução numa perspectiva de mudança no modelo assistencial hospitalocêntrico para um modelo de atenção integral; articulação de ações individuais e coletivas de vigilância em saúde.

De acordo com Minayo-Gomez e Lacaz (2005), o que existem hoje em saúde do trabalhador, são evidenciados problemas cruciais, inclusive deficiências do próprio funcionamento do SUS, merecendo destaque: 1) A persistência do modelo assistencial centrado na consulta médica individual em detrimento das ações coletivas, apesar da concepção diferenciada do que seja saúde do trabalhador; 2) As insuficientes ou inexistentes, quantitativa e qualitativamente, ações de promoção e proteção da saúde; 3) A carência e despreparo dos profissionais do setor para a abordagem das questões de saúde dos trabalhadores; 4) As informações sobre enfermidades, fatores de risco ou formas de promoção e prevenção são insuficientes, inacessíveis ou pouco ágeis; e 5) As dificuldades para a implementação de uma real e efetiva participação dos trabalhadores.

De acordo com VASCONCELLOS (2007) hoje o aparelho de Estado brasileiro, voltado para a atenção à saúde do trabalhador, está estruturado basicamente em quatro ministérios (Saúde, Trabalho e Emprego, Previdência Social e Educação), em duas fundações (Fundação Jorge Duprat Figueiredo de Medicina e Segurança do Trabalho - Fundacentro, e Fundação Oswaldo Cruz - Fiocruz) e em centros de atenção à saúde do trabalhador do SUS, que compõem a Rede Nacional de Atenção Integral à Saúde do Trabalhador (Renast), especialmente os Centros de Referência em Saúde do Trabalhador (CERESTS) inseridos nas secretarias estaduais e municipais de saúde. Mas há pouca, ou nenhuma, articulação entre essas estruturas. Suas atribuições, por vezes, superpõem-se, como no que se refere às informações, à VISAT, à reabilitação, à formação e à fiscalização.

Outrossim, no ano de 2011, quando a então presidenta da república Dilma Rousseff, assinou juntamente com os ministros do Trabalho e emprego, da Previdência Social e da Saúde, o decreto que regulamenta a Política Nacional de Segurança e Saúde no Trabalho (PNSST) - Portaria 1.823 de 23 de agosto de 2012. De acordo com o decreto, a PNSST tem por objetivos a promoção da saúde, a melhoria da qualidade de vida do trabalhador, a prevenção de acidentes e de danos à saúde relacionados ao trabalho (BRASIL, 2011).

No processo histórico do mundo do trabalho, observaram-se muitas transformações significativas. E para Dejours (2004), depois de ter atribuído uma importância crucial à organização do trabalho, o interesse dos pesquisadores foi canalizado para o distanciamento que há entre o trabalho prescrito e 
trabalho real e também para a maneira como os homens e as mulheres conseguem enfrentar essa distância, nas condições de negação da realidade das dificuldades que esta distância lhes causa.

Porém, quanto maior é a distância entre o trabalho prescrito e o trabalho real, maior será o espaço para adoecimentos. E os profissionais da área de saúde, será que estão preparados (exemplo dos agentes sanitários dentre outros) para o enfrentamento de tais realidades? Hoje o ambiente do trabalho pode ser dinâmico, como trabalhar em casa (exemplo sapataria, fabril dentre outros), mas as condições em que este trabalhador executa esta atividade? Como é sua exposição neste ambiente? Riscos ligados à qualidade, ergonomia, dentre outros.

A busca por estas respostas pode ser encontrada em investigações pertinentes a estudos e pesquisas no contexto da saúde trabalhador. Tentando encontrar resultados desta exploração, através destes trabalhadores, com o intuito de minimizar estes dados e potencializar ações voltadas a prevenção e promoção da saúde da classe trabalhadora.

Neste sentido, Beuren (2004) acrescenta que a preocupação com o conhecimento da realidade é uma constante na vida dos homens, pois a pesquisa apresenta-se como uma forma de investigação que tem por finalidade buscar algumas respostas às indagações da sociedade por meio de procedimentos científicos.

Verifica-se que o contexto investigativo possibilitou a realização desta pesquisa e, ainda mais, com a intenção em um segundo momento, de trazer causas que tem comprometido a saúde deste trabalhador neste seguimento de segurança privada.

\section{SAÚDE DO TRABALHADOR E A SAÚDE OCUPACIONAL}

De acordo com o Ministério da Saúde (2001), no Brasil, as relações entre trabalho e saúde do trabalhador conformam um mosaico, coexistindo múltiplas situações de trabalho caracterizadas por diferentes estágios de incorporação tecnológica, diferentes formas de organização e gestão, relações e formas de contrato de trabalho, que se refletem sobre o viver, o adoecer e o morrer dos trabalhadores.

Ao longo do tempo, o campo saúde do trabalhador vem adquirindo conquistas, porém cabe ressaltar que mesmo diante de avanços estes profissionais ainda estão expostos a riscos constantes que ameaçam sua saúde e integridade físico e mental.

Mesmo diante de políticas públicas, é notório as contradições encontradas e a realidade vivida por estes trabalhadores no exercer de suas funções. Desta forma, este estudo realizado, vai de encontro as lacunas desta relação entre trabalho e o processo saúde/doença. Segundo definição de Costa (2009) defini que as doenças ocupacionais são moléstias de evolução lenta e progressiva, originárias de causa igualmente gradativa e durável, vinculadas às condições de trabalho.

Diante deste estudo, foram detectados os postos de atuação dos trabalhadores que apresentaram problemas de transtornos psiquiátricos, no período analisado de janeiro de 2012 a dezembro de 2015, são eles: Portaria Afastamento, Vigilância de Afastamento, Vigilância Férias, Condomínios, Agronegócios, Usinas, Mineradoras e Logísticas Malha Ferroviária.

Cabe descrever, mediante experiência de campo advinda da oportunidade de acesso a estes locais, que os postos de afastamento e de férias são bastante peculiares. Neles atuam os profissionais que repõem ausências (férias e ou atestados), portanto estão em vários locais diferentes (clientes), todos os meses. Exigindo assim, uma adequação e adaptação as normas e procedimentos de cada posto, tendo que ser treinado quase que constantemente e lidando com diferentes tipos de clientes, gestores e colegas de profissão. São postos que exigem muito e consequentemente desencadeiam desgastes físico e mental dos que neles são escalados para atuação.

Outro posto de serviço apresentado e também bastante peculiar é o de Condomínios, onde o controle de acesso é o ponto mais delicado e preocupante deste segmento. É preciso bastante atenção para setores de riscos tendo a preocupação em manter o local tranquilo e seguro para os moradores. Manter a ordem e a segurança, recepcionando e controlando o acesso não só dos moradores, mas também dos visitantes e fornecedores, tendo assim turnos de trabalho diurno e noturno bastante movimentados, com uma rotatividade grande de pessoas. 
Do mesmo modo, os postos dos setores Industrial e de Agronegócios exigem muito foco, principalmente nos locais de produção e no controle de acesso de materiais e pessoas, por isso é necessário perfil de trabalhadores específicos para estes locais. Os clientes destes segmentos, na sua grande maioria, são empresas multinacionais, portanto, os profissionais que nelas atuarem, precisam cumprir com bastante rigor as normas e procedimentos estipulados, focando a atuação em situações de risco, identificando e alertando o cliente da vulnerabilidade que estão expostos. $E$ assim, 0 profissional de segurança, tem que ser bastante treinado para adaptar e cumprir as normas e exigências do cliente e também as normas da empresa contratante de origem.

De forma análoga, empresas que cuidam da logística e malha ferroviária, também apresenta um nível alto de risco e de exigência de atuação dos profissionais de segurança. Estas linhas ferroviárias estão espalhadas por diversas localidades (tanto urbano, quanto rural) e estes trabalhadores estão expostos a diversas situações, que os levam a um desgaste físico e mental. Também, por se tratar de cliente multinacional, tem suas normas e procedimentos pertinentes do setor, exigindo cumprimento com bastante rigor dos profissionais de segurança, devido alto risco do segmento.

Sabe-se que um posto de trabalho bastante delicado em atuação é o setor de Mineradoras. São locais bastante visados por marginais e os profissionais estão constantemente expostos a situações de bastante riscos e violência. Geralmente são cliente multinacionais, que também prezam pelo rigor do cumprimento das suas normas e procedimentos do segmento de mineração.

Diante deste depoimento, podemos refletir sobre o quanto os processos produtivos de trabalho, comprometem não somente o aspecto físico, mas também no psicológico dos profissionais, mesmo não sendo evidenciado no ASO categoria CID F (mental).

Em janeiro de 2013, conforme o "Acompanhamento Mensal dos Benefícios Auxílios-Doença Acidentários Concedidos segundo os Códigos da CID-10" do INSS, do total de 23.062 auxílios concedidos, em primeiro lugar aparecem as lesões, envenenamentos e 25 traumatismos (14.859 auxílios concedidos), em segundo as doenças do sistema osteomuscular (5.493), e em terceiro os transtornos mentais e comportamentais (951). Esse dado é apenas um indicativo da realidade de trabalhadores segurados (INSS, 2013).

Desta maneira, podemos acrescentar que, a Saúde Ocupacional (SO) é uma área que cuida para que o local de trabalho não ofereça riscos para o trabalhador. No entanto, é de responsabilidade do Serviço de Saúde e Segurança do Trabalho (SST) prevenir, proteger e realizar ações que promovam a saúde no ambiente de trabalho, onde estes possam atuar satisfeitos, motivados, viabilizando ganhos tanto de produtividade quanto de cunho profissional. Contudo, sabe-se que a realidade nos remete a números alarmantes de doenças profissionais e acidentes de trabalho, resultando saldos negativos desta relação trabalho/saúde.

E, relacionando ao estudo proposto, para Rossi (2007) entre as principais causas do estresse estão as seguintes: incerteza, sobrecarga de trabalho, relações interpessoais, tecnologia, desempenho da tarefa, problemas emocionais, assédio moral, rituais e procedimentos desnecessários, entre outros. Às diversas causas do estresse somam-se os fatores, que Ballone (2002) já havia detectado em relação ao estresse ocupacional, que são: o aumento do volume de trabalho; os conflitos diários no trabalho; as pressões sofridas pelo trabalhador; a falta de compreensão e tolerância da chefia, que também se vê pressionada; todo um ambiente desfavorável ao sujeito e o exercício de funções que são sentidas como inadequadas.

Os fatores relacionados ao estresse ocupacional podem resultar em: afastamento do trabalho; intervenção hospitalar; desequilíbrio familiar; perda do emprego e constrangimento no trabalho e na sociedade. Tais elementos ou situações podem gerar consequências também para a organização, podendo ocorrer: perda de oportunidades no mercado; queda de produtividade; intensificação do absenteísmo e prejuízos financeiros (PAIVA, COUTO, 2007).

\section{SAÚDE MENTAL E TRABALHO}

De acordo com SILVA (2011), quando estudamos as repercussões do trabalho sobre a mente humana, verificamos que, ao longo do desenvolvimento de diferentes áreas do conhecimento, esse tema tem sido considerado e pesquisado, tanto por disciplinas que estudam a saúde humana quanto por um grupo de disciplinas que, não estando voltadas para o estuda da saúde, tem, ao abordar 
temáticas vinculadas ao trabalho, enfocando aspectos que dizem respeito à constituição do desgaste mental e à construção de resistências diante das transformações interconectadas do trabalho e dos fenômenos de dominação.

Cabe destacar neste estudo sobre um marco importante para a área de saúde mental que foi a criação do Centro de Atenção Psicossocial (CAPS), que assume papel estratégico na organização da rede comunitária de cuidados, através Portaria GM/MS no 336, de 19 de fevereiro de 2002, do Ministério da Saúde.

De acordo com o Ministério da Saúde (2003), as pessoas atendidas nos CAPS são aquelas que apresentam intenso sofrimento psíquico, que lhes impossibilita de viver e realizar seus projetos de vida. São, preferencialmente, pessoas com transtornos mentais severos e/ou persistentes, ou seja, pessoas com grave comprometimento psíquico, incluindo os transtornos relacionados às substâncias psicoativas (álcool e outras drogas) e também crianças e adolescentes com transtornos mentais.

No CAPS, entre várias oficinas, uma das que se destaca é a geradora de renda: servem como instrumento de geração de renda através do aprendizado de uma atividade específica, que pode ser igual ou diferente da profissão do usuário. As oficinas geradoras de renda podem ser de: culinária, marcenaria, costura, fotocópias, venda de livros, fabricação de velas, artesanato em geral, cerâmica, bijuterias, brechó, etc. (BRASIL, 2004).

Os transtornos evidenciados neste estudo, sobre uso de substâncias psicoativas, mostram os prejuízos para a saúde do trabalhador e também perdas para a classe empresarial. Nos resultados, o CID deste seguimento, apresenta um número reduzido em atestados (19), porém um alto número de dias ausentes no trabalho (2302). Isso se deve porque, trabalhadores acometidos por estes transtornos, requerem tratamentos de longa duração. $O$ transtorno mental e comportamental devido ao uso de álcool (F10.0), foi o CID que apresentou nos resultados, o maior número de dias ausentes no trabalho (1129 dias).

Dados do Ministério da Previdência Social, indicam os transtornos mentais como importante contribuinte na casuística entre 2000 e 2011 para o benefício Auxílio Doença que representam 4,76\% de todos os afastamentos. Dentre eles, os Episódios depressivos (F32) com peso de 3,55\% e Outros Transtornos Ansiosos (F41) com peso de 1,21\%. Juntos totalizam 13.243.873 ocorrências, no período exposto (BRASIL, 2003).

No Brasil, de acordo com Pena (2011) os problemas de saúde mental relacionados ao trabalho não são novos. Um dos primeiros registros de "surtos" de depressão relacionado ao trabalho no país foi o relato do banzo - o sofrimento dos escravos africanos trazidos para o Brasil. A desterritorialização e a saudade da África os levou a cometer atos extremos como comer terra nas ruas do Rio de Janeiro, manifestação clara de um sofrimento incalculável e aterrorizador.

A relação entre saúde mental e trabalho constitui o objeto dos estudos da Saúde Mental Relacionada ao Trabalho (SMRT). Considerando a unicidade corpo-mente, que torna saúde geral mente indissociáveis, podemos dizer que esse objeto é a inter-relação entre o trabalho e os processos saúdedoença cuja dinâmica se inscreve mais marcadamente nos fenômenos mentais, mesmo quando sua natureza seja eminentemente social. Uma precisão ainda maior exige que seja incluído nesse objeto não apenas o trabalho, mas também a falta de trabalho (SILVA, 2011).

Portanto, podemos acrescentar que a doença para o trabalhador significa fragilidade, queda de desempenho, perda nos resultados, gastos a mais, preocupação em ter que ausentar e aliado a tudo isso o receio do risco em perder o emprego e ficar sem trabalho.

Sobre a vida nervosa nas classes trabalhadoras urbanas, Duarte (1986) descreve que é possível identificar todo um conjunto de imagens e representações em que a ideia do nervoso, nervosismo ou "sistema nervoso" se conecta às restrições sentidas, corporal ou mentalmente, na situação de trabalho. Em resumo, há uma ideia central de perda de liberdade relacionada ao sofrimento mental. A concepção de que as forças e os elementos que constringem o corpo e seus movimentos livres irritam os nervos ou a cabeça se faz notar em vários discursos.

Diante dos resultados, os episódios e transtornos depressivos que mais prevaleceram no período, foram: Episódio depressivo leve (F32.0), foi o código da CID-10 que apresentou maior número de atestados, seguido do Episódio depressivo grave (F32.2) e episódio depressivo moderado (F32.1). 
A depressão consiste em um grande problema social, devido aos custos pessoais, ao prejuízo à saúde como um todo e à qualidade de vida. Constitui-se também em problema para as empresas, porque gera custos causados pela perda de produtividade, maior número de faltas ao trabalho, maior número de afastamentos e pelo prejuízo ao profissional.

De acordo com a Organização Mundial da Saúde, a depressão ocupa o segundo lugar dentre as doenças que causam incapacidade no trabalho, e a projeção é que até 2020 ela esteja no topo da lista. Ainda segundo a OMS, a média de falta no trabalho de um indivíduo com depressão é de sete dias por mês, enquanto a média geral é uma vez a cada 30 dias. Em linha com essa afirmação, uma pesquisa realizada pela Universidade de Brasília (UnB) em parceria com o Instituto Nacional de Seguro Social (INSS) revela que $48,8 \%$ dos trabalhadores que se afastam por mais de 15 dias do trabalho sofrem com algum transtorno mental, sendo a depressão o principal deles (OMS, 1993).

Além disso, essas manifestações do sofrimento dos trabalhadores na atualidade estão entre os grandes problemas de saúde pública que exigem a investigação e intervenção da vigilância. Como visto, as condições de trabalho na atualidade são marcadas por uma mobilização sem precedentes da subjetividade, em um contexto em que o apoio social aos trabalhadores é fragilizado (RENAULT, 2006).

As novas formas de organização do trabalho, tal qual o Toytismo, são indutoras de maior cansaço e ansiedade em trabalhadores, fruto das pressões da variedade de demandas e exigências continuas nos padrões de qualidade, como pode ser observado na busca por um modelo de "defeito zero" (CASTELLS, 1999).

\section{PSICOLOGIA DO TRABALHO}

Este termo, psicologia do trabalho, estuda o homem em seu ambiente de trabalho e suas ações estão voltadas para estes profissionais, tais como: trabalho em equipe, comportamento humano, avaliação, comunicação e feedback, saúde e segurança, motivação, absenteísmo e rotatividade, dentre outros. Ainda assim, o desenvolvimento da Psicologia do Trabalho se fez expandindo e aprofundando tanto $o$ estudo da dimensão cognitiva quanto o da psicoafetiva, penetrando no exame da intersubjetividade e, mais recentemente, dos fenômenos microssociais e micropolíticos (SILVA, 2011).

Em geral, as análises revelam o quanto o atual modo de produção-consumo conformam complexos e heterogêneos problemas de saúde mental. Muitos deles decorrem das características técnicas e sociais da gestão e organização do trabalho pós-fordistas, que induzem novos sofrimentos físicos, psíquicos e sociais (GORZ, 2005; LAZZARATO, NEGRI, 2001).

Podemos acrescentar que 0 trabalho na atualidade, passa a ser observado e analisado com rigor, quanto a seu papel relacionado a saúde-transtorno mental. Os profissionais da saúde e pesquisadores tem explorado a temática com a finalidade de evidenciar as dimensões onde o trabalho possa desencadear psicopatologias.

A Organização Internacional do Trabalho (OIT) recebe atenção especial de Dejours (2004) por diferentes vias: a organização do trabalho ocasiona insatisfação, quer pelo esvaziamento de sentido, quer pela violentação de uma "economia psicossomática" que seria singular para cada trabalhador. Por outro lado, temos a questão da subjetividade do tema, que ao contrastar ou até ser associada ou não às condições do ambiente físico, químico e biológico do trabalho, muitas vezes desrespeita as necessidades do corpo.

Em outras palavras, temos questões inerentes neste cenário, pois em muitas vezes se faz presente por meio de imposições organizacionais que ferem o amor-próprio, também degradam a auto-imagem e, dentro da visão psicanalítica, acarretam uma ferida narcísica.

A psicologia organizacional foca principalmente nos processos organizacionais relacionados a recrutamento e seleção de pessoas, educação e desenvolvimento humano (treinamentos/capacitações), clima organizacional, avaliação de performance individual e coletiva, cargos e salários, desligamentos, aplicação de testes, comportamento organizacional, desenvolvimento de liderança e demais necessidade esporádicas. 


\section{SEGURANÇA PRIVADA NO BRASIL E NO MUNDO}

A terceirização é um fenômeno mundial. Seu aparecimento se deu durante a $2^{\text {a }}$ Guerra Mundial, quando a indústria bélica americana e britânica, pressionada pela urgência e na busca pela eficiência, começou a dedicar a terceiros as atividades não vitais à produção de armamentos, equipamentos, veículos e navios. Naquela época, as principais áreas a terem seus serviços terceirizados foram segurança, limpeza e conservação e transportes. Mais tarde, e com o aparecimento de novas atividades e tecnologias, incorporaram-se os serviços de alimentação, contabilidade, assessoria jurídica, recursos humanos, serviços de informática e processamento de dados e atendimento ao cliente (FENAVIST, 2014 pág. 64).

O crescimento do setor de vigilância privada, no Brasil e no mundo, se deu de forma gradativa desde o pós-guerra. Contudo foi intensificado a partir dos anos 1980, principalmente com a disseminação das ideias contidas em um relatório do Departamento de Justiça dos Estados Unidos, no qual o setor foi considerado parte integrante da luta contra o crime (ZANETIC, 2005).

No Brasil, as primeiras empresas do setor de vigilância privada surgiram nos anos 1960, devido ao aumento do número de assaltos a bancos.

ZANETIC (2005) complementa que este tipo de crime já vinha aumentando no país desde 1950, mas cresceu sobremaneira nas ações de grupos de esquerda combatentes da ditadura política brasileira fazendo com que em 1969 o Estado obrigasse os estabelecimentos bancários a contratar ou montar seus próprios serviços de vigilância.

No Brasil, a Lei no 7.102, de 20 junho de 1983, do Ministério da Justiça, rege o setor de segurança privada no Brasil. Dispõe sobre segurança para estabelecimentos financeiros, estabelece normas para constituição e funcionamento das empresas particulares que exploram serviços de vigilância e de transporte de valores e dá outras providências.

A expansão do setor de segurança privada vem acompanhando o crescimento da criminalidade, a percepção social da violência e a sensação de insegurança (BRASIL, 2009). Segurança privada se tornou o elemento central do novo e difundido padrão de segregação urbana (CALDEIRA, 2000), reforçando a busca por soluções individuais para garantir a integridade física e patrimonial em enfrentamento à violência. $\mathrm{O}$ segmento oferece amplo leque de serviços e produtos: segurança eletrônica, patrimonial (bancária, comércio, indústria, residencial, condomínios, shoppings etc.), escolta, monitoramento no transporte de valores e cargas, treinamento de profissionais que atuam na área, blindagem de veículos e, mais recentemente, gestão de presídios (ZANETIC, 2005).

Dados mais atuais, apresentado no IV Estudo do Setor da Segurança Privada, demonstram que houve um crescimento significativo do setor da segurança privada no Brasil na última década em $68 \%$, em número de empresas para 2013. Estima-se que essas empresas movimentaram no Brasil cerca de $R \$$ 43 bilhões/ano, empregando formalmente cerca de 706,5 mil trabalhadores (FENAVIST, 2014).

\section{RESULTADOS}

Dos resultados encontrados neste estudo, o episódio mental que apresentou maior número de atestado, foi o CID F41.0 Transtorno de Pânico, com 59 atestados de saúde ocupacional (ASO), totalizando 1216 dias de ausência no trabalho. Este transtorno refere-se a uma ansiedade paroxística episódica, que na realidade dos profissionais de segurança privada, estão intimamente relacionados aos boletins de violência (roubos, assaltos, invasões, agressões) o qual estes trabalhadores estão sujeitos no dia a dia do trabalho.

Os dados analisados e avaliados evidenciaram 58 tipos de transtornos mentais e comportamentais, codificados pela CID-10, categoria "F" (mental) psiquiátricos, evidenciados em 389 atestados de saúde), entregues por 281 trabalhadores no setor de Serviço Especializado em Engenharia de Segurança e Medicina do Trabalho (SESMT) da empresa, no período de 2012 a 2015.

O Quadro 1 aparece os quinze transtornos mentais e comportamentais de maior prevalência em número de atestados, dias de ausência no trabalho e dias de auxílio custeados pela organização, do período analisado de janeiro 2012 a dezembro de 2015. São eles: F41.0 - Transtorno de pânico (ansiedade paroxística episódica), que apresentou 59 atestados, 1216 dias de ausência e 217 dias de auxílio.; F32.0 - Episódio depressivo leve, apresentou 55 atestados, 443 dias de ausência e 281 dias 
de auxílio; F41.1 - Ansiedade generalizada, que apresentou 28 atestados, 1380 dias de ausência e 132 dias de auxílio; F32.2 - Episódio depressivo grave sem sintomas psicóticos, que apresentou 27 atestados, 2331 dias de ausência e 285 dias de auxílio.

Quadro 1 - Transtornos mentais e comportamentais mais frequentes na empresa do setor de segurança privada, estudados por número de atestado, dias de ausência no trabalho e dias de auxílio custeados pela organização, Uberlândia, Minas Gerais, Brasil, no período de 2012 a 2015.

\begin{tabular}{|c|c|c|c|c|}
\hline CID & Descrição & $\begin{array}{l}\text { Atestados } \\
\text { (N) }\end{array}$ & $\begin{array}{l}\text { Ausências } \\
\text { (dias) }\end{array}$ & $\begin{array}{l}\text { Auxílio } \\
\text { (dias) }\end{array}$ \\
\hline F41.0 & Pânico: ansiedade paroxística episódica & 59 & 1216 & 287 \\
\hline F32.0 & Episódio depressivo leve & 55 & 443 & 281 \\
\hline F41.1 & Ansiedade generalizada & 28 & 1380 & 132 \\
\hline F32.2 & Episódio depressivo grave sem sintomas psicóticos & 27 & 2331 & 285 \\
\hline F43.0 & Reação aguda ao stress & 26 & 1430 & 141 \\
\hline F32.1 & Episódio depressivo moderado & 21 & 1266 & 179 \\
\hline F41.2 & Transtorno misto ansioso e depressivo & 17 & 184 & 139 \\
\hline F41.9 & Transtorno ansioso não especificado & 15 & 194 & 53 \\
\hline F33.2 & $\begin{array}{l}\text { Transtorno depressivo recorrente, episódio atual grave } \\
\text { S/S sint. psicóticos }\end{array}$ & 11 & 858 & 125 \\
\hline F32.9 & Episódio depressivo não especificado & 9 & 120 & 58 \\
\hline F43.1 & Estado de stress pós-traumático & 8 & 1025 & 49 \\
\hline F40.0 & Agorafobia & 7 & 38 & 38 \\
\hline F33.1 & $\begin{array}{l}\text { Transtorno depressivo recorrente, episódio atual } \\
\text { moderado }\end{array}$ & 7 & 111 & 52 \\
\hline F10.0 & $\begin{array}{l}\text { Transtorno mental e comportamental devido ao uso de } \\
\text { álcool }\end{array}$ & 6 & 1129 & 6 \\
\hline F43.2 & Transtorno de adaptação & 6 & 58 & 42 \\
\hline \multicolumn{2}{|l|}{ TOTAL } & 302 & 11783 & 1867 \\
\hline
\end{tabular}

Fonte - SESMT da empresa, 2016. Org.: AUTORES, 2019.

Já no F43.0 - Reação aguda ao stress, apresentou 26 atestados, 1430 dias de ausência e 141 dias de auxílio; F32.1- Episódio depressivo moderado, apresentou 21 atestados, 1266 dias de ausência e 179 dias de auxílio; F41.2 - Transtorno misto ansioso e depressivo, apresentou 17 atestados, 184 dias de ausência e 139 dias de auxílio; F41.9 - Transtorno ansioso não especificado, apresentou 15 atestados, 194 dias de ausência e 53 dias de auxilio; F33.2 - Transtorno depressivo recorrente, episódio atual 
grave sem sintomas psicóticos, apresentou 11 atestados, 858 dias de ausência e 125 dias de auxílio; F32.9 - Episódio depressivo não especificado, apresentou 9 atestados, 120 dias de ausência e 58 dias de auxílio; F43.1- Estado de stress pós-traumático, apresentou 8 atestados, 1025 dias de ausência e 49 dias de auxílio.

Por outro lado, no F40.0 - Agorafobia, apresentou 7 atestados, 38 dias de ausência e 38 dias de auxílio; F33.1- Transtorno depressivo recorrente, episódio atual moderado, apresentou 7 atestados, 111 dias de ausência e 52 dias de auxílio; F10.0- Transtornos mentais e comportamentais devidos ao uso de álcool, apresentou 6 atestados, 1129 dias de ausência e 6 dias de auxílio; F43.2 - Transtorno de adaptação, apresentou 6 atestados, 58 dias de ausência e 42 dias de auxílio. Estes códigos da CID correspondem a $78 \%$ do total de atestados apresentados na empresa, no período em análise.

O transtorno do pânico (F41.0) é o código da CID que apresentou a maior quantidade de atestados no período descrito, seguido do episódio depressivo leve (F32.0) e da ansiedade generalizada (F41.1). Já o episódio depressivo grave sem sintomas psicóticos (F32.2) foi o transtorno que apresentou maior número de dias ausente no trabalho, seguidos da reação aguda ao stress (F43.0) e ansiedade generalizada (F41.1).

Já o Quadro 2 apresenta a prevalência dos transtornos mentais e comportamentais devido ao uso e abuso de substâncias psicoativas, descrevendo a quantidade de atestados versos o número de dias ausente no trabalho. Dentre eles: F10.0 - Transtornos mentais e comportamentais devidos ao uso de álcool, que apresentou 6 atestados e 1129 dias de ausência; F14.2 - Transtornos mentais e comportamentais devidos ao uso da cocaína - síndrome de dependência, que apresentou 4 atestados e 749 dias de ausência; F19.2 - Transtornos mentais e comportamentais devido ao uso de múltiplas drogas e ao uso de outras subst. Psicoativas (síndrome da dependência), apresentou 3 atestados e 248 dias de ausência.

Quadro 2 - Transtornos mentais e comportamentais devido ao uso e abuso de substâncias psicoativas, apresentados pelos trabalhadores que atuam no setor de segurança privada, descritos em número de atestado e dias de ausência no trabalho, Uberlândia, Minas Gerais, Brasil, período de 2012 a 2015.

\begin{tabular}{|c|c|c|c|}
\hline Cód. & Descrição & os (N) & $\begin{array}{c}\text { Atestad } \\
\text { as (dias) }\end{array}$ \\
\hline F10.0 & $\begin{array}{c}\text { Transtornos mentais e comportamentais devidos ao } \\
\text { uso de álcool }\end{array}$ & 6 & 1129 \\
\hline F14.2 & $\begin{array}{c}\text { Transtornos mentais e comportamentais devidos ao } \\
\text { uso da cocaína - Síndrome da Dependência }\end{array}$ & 4 & 248 \\
\hline F19.2 & $\begin{array}{c}\text { Transtornos mentais e comportamentais devido ao } \\
\text { uso de múltiplas drogas - Síndrome da Dependência }\end{array}$ & 3 & 171 \\
\hline F19.0 & $\begin{array}{c}\text { Transtornos mentais e comportamentais devidos ao } \\
\text { uso de múltiplas drogas intoxicação aguda }\end{array}$ & 3 & 3 \\
\hline F11.1 & nocivo de opiácios & 1 & 2 \\
\hline F11.0 & Transtornos mentais e comportamentais devido uso & 2 & $\mathbf{2 3 0 2}$ \\
\hline TOTAL opios - intoxicação aguda
\end{tabular}

Fonte - SESMT da empresa, 2016. Org.: AUTORES, 2019.

Já os que apresentaram o F19.0 - Transtornos mentais e comportamentais devidos ao uso de múltiplas drogas e ao uso de outras subst. psicoativas- intoxicação aguda, que apresentou 3 atestados e 171 dias de ausência; F11.1 - Transtornos mentais e comportamentais devidos ao uso de opiácios - uso DOI:http://dx.doi.org/10.14393/Hygeia153247545 Hygeia 15 (32): $112-126$, junho/2019 página 122 
nocivo para saúde, que apresentou 1 atestado e 3 dias de ausência; F11.0- Transtornos mentais e comportamentais devidos ao uso de opiácios - intoxicação aguda, que apresentou 2 atestados e 2 dias de ausência.

Estes transtornos apresentaram um reduzido número em atestados (19), porém um alto número de dias ausentes no trabalho (2302). Isso se deve porque, trabalhadores acometidos por estes códigos da $\mathrm{CID}$, requerem tratamentos de longa duração.

No Gráfico 1 há o detalhamento dos códigos da CID-10 F ("Grupo dos 30") onde são descritos os episódios e transtornos depressivos que mais prevaleceram no período, conforme classificação. Observa-se que o episódio depressivo leve (F32.0), foi o código da CID-10 que apresentou maior número de atestados, seguido do episódio depressivo grave (F32.2) e episódio depressivo moderado (F32.1).

Gráfico 1 - Distribuição do volume de atestados e dias de afastamento mais frequentes da CID-10 classificados entre o grupo dos 30. Uberlândia/MG, 2019.

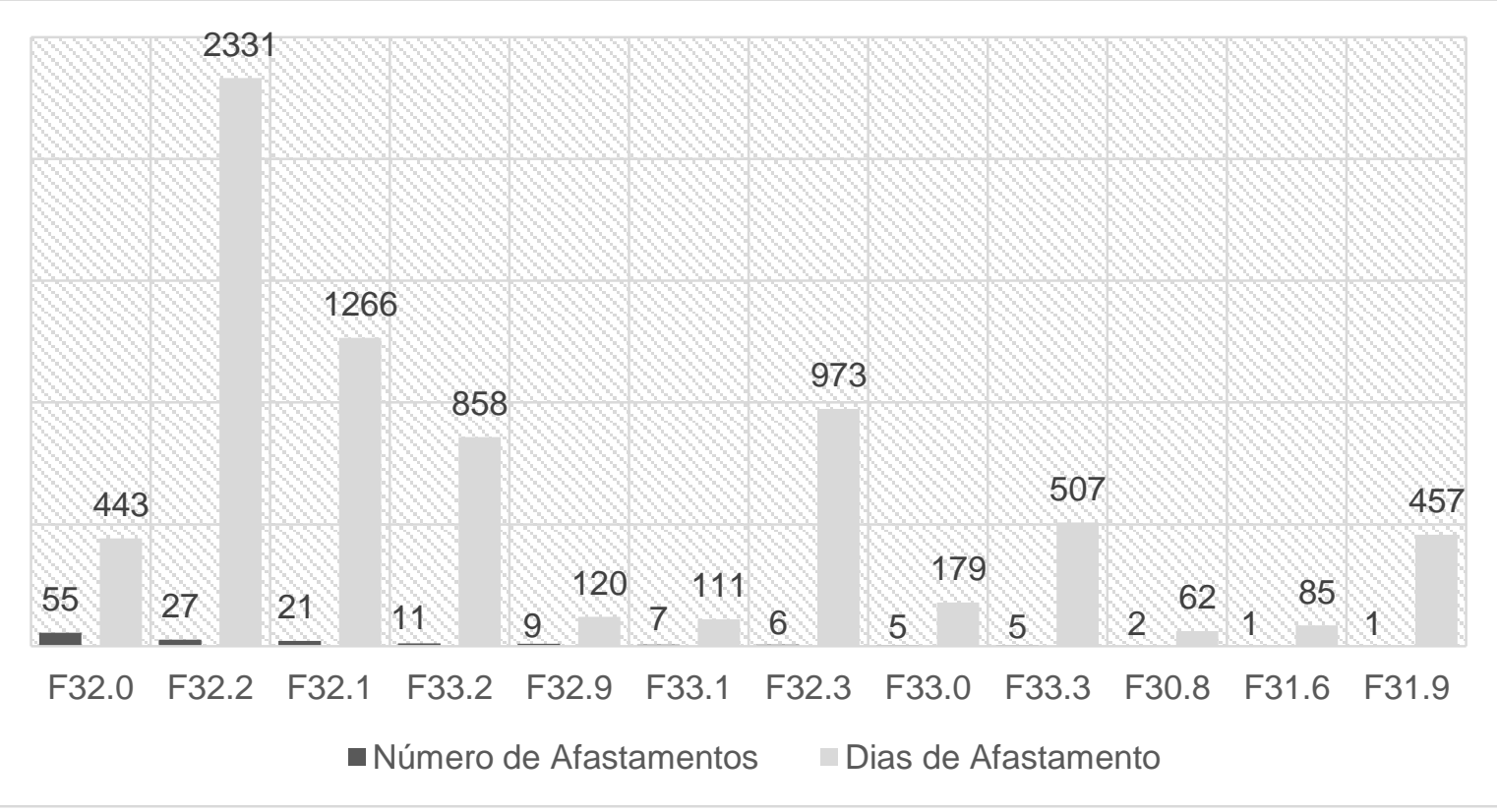

CID-10 - Transtorno depressivo bipolar não especificado (31.6); Episódio depressivo leve (F32.0); Episódio depressivo grave sem sintomas psicóticos (F32.2); Episódio depressivo moderado (F32.1); Transtorno depressivo recorrente, episódio atual grave sem sintomas psicóticos (F33.2); Episódio depressivo não especificado (F32.9); Transtorno depressivo recorrente, episódio atual moderado (F33.1); Episódio depressivo grave com sintomas psicóticos (F32.3); Transtorno depressivo recorrente, episódio atual leve (F33.0); Transtorno depressivo recorrente, episódio atual grave com sintomas psicóticos (F33.3); Transtorno depressivo bipolar não especificado (F31.9). Fonte: SESMT da empresa, 2016. Org.: AUTORES, 2019.

\section{DISCUSSÃO}

Aponta-se que os profissionais que atuam no setor de segurança privada, tais como vigilante, porteiro, recepcionista, segurança pessoal, atendentes de monitoramento eletrônico e demais do setor administrativo, na sua grande maioria atuam em escala 12 horas por 36 horas, onde se tem turnos longos de trabalho interferindo em suas relações pessoais. E uma boa parte destes profissionais, realizam trabalhos informais em suas folgas, tendo assim uma rotina intensa de atividades, distanciando cada vez mais dos seus afetos e consequentemente a uma menor interação e qualidade de vida, desencadeando assim, transtornos e episódios evidenciados, principalmente nos códigos da CID de transtornos depressivos, que foram identificados com relevância, no estudo realizado. 
O estudo nos remete a um conjunto de fatores pertinentes do segmento de Segurança Privada, a serem considerados, pois contribuem para desencadeá-lo de adoecimentos mentais desta classe trabalhadora. As situações estressantes expostas no dia a dia dos postos e as exigências pertinentes dos segmentos dos setores, em um ritmo constante, podem levar ao adoecimento.

A violência seria outro fator bastante preocupante para os profissionais, pois estes estão sujeitos a ela, no seu dia a dia de trabalho. É sendo eles o primeiro alvo dos bandidos, pois estes trabalhadores estão ali para impedir a atuação destes meliantes. Várias são as situações de assaltos, roubos, invasões, que estes estão expostos e assim, desencadeando patologias, como as que foram identificadas no estudo em referência.

\section{CONCLUSÃO}

Conclui-se que os resultados evidenciados neste estudo vão de encontro com a realidade vivida por estes trabalhadores, apresentados nos atestados de saúde ocupacional, principalmente as evidencias dos transtornos mentais e comportamentais mais frequentes na empresa, estudados por número de atestados e dias de ausência do trabalhador.

E diante dos resultados encontrados, foram presentes nos CIDs que corresponderam a $78 \%$ do total de atestados apresentados na empresa, sendo que o transtorno do pânico (F41.0) foi o que apresentou a maior quantidade de atestados no período descrito no estudo, seguido do episódio depressivo leve (F32.0) e da ansiedade generalizada (F41.1), constatando com isso, o quanto os trabalhadores deste seguimento é acometido por fatores e situações que os levam a sofrimentos. Já o episódio depressivo grave sem sintomas psicóticos (F32.2) foi o transtorno que apresentou maior número de dias ausente no trabalho, seguidos da reação aguda ao stress (F43.0) e ansiedade generalizada (F41.1).

Verificou-se que devido ao cotidiano profissional desta categoria de trabalhadores, podem ser facilitadores ou geradores de um a adoecimentos de ordem biopsicossocial pois, muitas das vezes estes são expostos a fatores de riscos, atuando em locais isolados, sob alta pressão.

Contudo, espera-se com este trabalho, permita contribuir para a elucidação dos transtornos apresentados por estes profissionais, bem como despertar para a necessidade de promover ações e intervenções para que os setores públicos, privado e a área de saúde, de âmbito local e nacional, possam desenvolver ações que amenizem tais sofrimentos (físicos, psíquicos e sociais), promovendo assim, qualidade de vida e saúde para esta classe trabalhadora.

\section{REFERÊNCIAS}

ANTUNES, R. (Org.) A Dialética do Trabalho. São Paulo: Expressão Popular, 2004.

BALLONE, G. J. (2002). Estresse no trabalho. Disponível em: http://www.psiqweb. med.br/site/?area=NO/LerNoticia\&idNoticia=67. Acesso em 30 set. 2009

BEUREN, I. M. (org.). Como elaborar trabalhos monográficos em contabilidade: teoria e prática. $2^{\underline{a}}$ ed. São Paulo: Atlas, 2004.

BRASIL. Ministério da Saúde. A Política do Ministério da Saúde para atenção integral a usuários de álcool e outras drogas. Brasília: Ministério da Saúde, 2003.

Ministério da Justiça. Texto base da 1aㅡ Conferência Nacional de Segurança Pública. Brasília: PRONASCI, 2009.

Casa Civíl. Decreto oㅜ 7602 de 7 de novembro de 2011. Dispõe sobre a Política Nacional de Segurança e Saúde no Trabalho - PNSST. Casa Civil. Subchefia para Assuntos Jurídicos. Diário Oficial da União, nov. 2011. 
BRAGA, L. C.; CARVALHO, L. R.; BINDER, M. C. P. Condições de trabalho e transtornos mentais comuns em trabalhadores da rede básica de saúde de Botucatu (SP). Ciênc. Saúde Coletiva, v. 15 , supl. 1 , p. 1585-1596, jun. 2010. https://doi.org/10.1590/S1413$\underline{81232010000700070}$

CALDEIRA, T. P. R. Cidade dos muros: crime, segregação e cidadania em São Paulo. São Paulo: Editora 34; Edusp, 2000.

CASTELLS, M. A sociedade em rede. Era da informação: Economia, Sociedade e Cultura. 1 ed. São Paulo: Paz e Terra, 1999.

CAVALHEIRO, G.; TOLFO, S. R. Trabalho e depressão: um estudo com profissionais afastados do ambiente laboral. Psico-USF, Itatiba, v. 16, n. 2, p. 241-249, 2011. https://doi.org/10.1590/S1413-82712011000200013

COSTA, M. R. A Violência Urbana e Particularidade da Sociedade Brasileira? São Paulo Perspec. v. 13, n. 4 São Paulo Oct./Dec. 1999. https://doi.org/10.1590/S0102-88391999000400002

COSTA, H.J. Manual de Acidente do Trabalho. 3. ed. Curitiba: Juruá, 2009. p. $74-75$

DEJOURS, C.; ABDOUCHELI E. Psicodinâmica do Trabalho: contribuições da escola dejouriana à análise da relação prazer, sofrimento e trabalho. São Paulo: Atlas. 1994.

DEJOURS, C. Da Psicopatologia à Psicodinâmica do Trabalho. Rio de Janeiro: Editora Fiocruz. 2004.

DUARTE, L. F. D. Da vida nervosa nas classes trabalhadoras urbanas. Rio de Janeiro: Jorge Zahar, 1986.

FENAVIST. Estudos do Setor de Segurança Privada. Brasília/DF, 2012.

Estudos do Setor de Segurança Privada. Brasília/DF, 2014.

GORZ, A. O imaterial. Conhecimento, Valor e Capital. São Paulo. Anablume, 2005.

LACAZ, F. A. C. O programa de saúde dos trabalhadores da Secretaria de Estado de Saúde de São Paulo: a agonia de uma proposta. Revista saúde em debate, v. 36, p. 41-47. 1992.

LACAZ, F. A. C. Saúde do trabalhador: um estudo sobre: um estudo sobre as formações discursivas da academia, dos serviços e do movimento sindical (1996). Tese de Doutorado (Faculdade de Ciências Médicas da Unicamp), Campinas. 1996

LAZZARATO, M.; NEGRI, A. Trabalho imaterial. Formas de vida e produção de subjetividade. Rio de Janeiro: DP\&A, 2001.

MACHADO J. M. H. Alternativas e processos de vigilância em saúde do trabalhador: a heterogeneidade da intervenção (1996). Tese de Doutorado (Escola Nacional de Saúde Pública, Fundação Oswaldo Cruz) 1996.

MINEO, J.R. et al. Pesquisa na área biomédica: do planejamento à publicação. Uberlândia: EDUFU, 2005.

MARTIN, D.; QUIRINO, J.; MARI, J. Depressão entre mulheres da periferia de São Paulo. Rev. Saúde Pública, v. 41, n. 4, p. 591-597, 2007. https://doi.org/10.1590/S0034-89102007000400013

MENEZES, L. S. A. Psicanálise e Saúde do Trabalhador: nos rastros da precarização do trabalho. São Paulo: Editora Primavera, 2012. 
MINAYO, M. C. S. O desafio do conhecimento. 10. ed. São Paulo: HUCITEC, 2007.

MINAYO-GOMEZ, C.; LACAZ, F. A. C. Saúde do trabalhador: novas e velhas questões. Ciênc. Saúde Coletiva, v. 10, n. 4, p. 797-806, 2005. https://doi.org/10.1590/S1413-81232005000400002

MURTA, S. G.; TRÓCCOLI, B. T. Avaliação de intervenção em estresse ocupacional. Psicologia: Teoria e Pesquisa, v. 20, n. 1, p. 39-47, 2004. https://doi.org/10.1590/S0102-37722004000100006

ODDONE, I. et al. Ambiente de trabalho: a luta dos trabalhadores pela saúde. Tradução: Salvador Obiol dFreitas. São Paulo: Hucitec, 1986.

OMS. Classificação de transtornos mentais da CID-10. Porto Alegre: Artmed. 1993.

PENA, P. G. L. A exploração do corpo no trabalho ao longo da história. In: VASCONCELLOS, L. C. F.; OLIVEIRA, M. H. B. (Org.). Saúde, Trabalho e Direito. 1 ed. Rio de Janeiro: EDUCAM, 2011, p. 85-123.

PEREIRA, L. 0 trabalho em causa na "epidemia depressiva". Tempo Social, v. 23, n. 1, p. 6795, jun. 2011.

RENAULT, Emmanuel. Du fordisme au post-fordisme: Dépassement ou retour de l'aliénation? Actuel Marx, v.1, n. 39, p. 89-105, 2006. https://doi.org/10.3917/amx.039.0089

SATO, L.; HESPANHOL, M. B.; OLIVEIRA, F. de. Psicologia social do trabalho e cotidiano: a vivência de trabalhadores em diferentes contextos micropolíticos. Psicol. Am. Lat. [online], $\mathrm{n}$. 15, 2008.

SILVA, E. S. Trabalho e Desgaste Mental: 0 direito de ser dono de si mesmo. São Paulo: Cortez, 2011.

TRIVIÑOS, A. N. S. Introdução à pesquisa em ciências sociais: a pesquisa qualitativa em educação. São Paulo: Atlas, 1987.

VASCONCELLOS, L.C.F. Saúde, trabalho e desenvolvimento sustentável: apontamentos para uma política de Estado. 2007. Tese de Doutorado (Escola Nacional de Saúde Pública), 2007.

VIEIRA, S. Metodologia científica para a área da saúde. 2. ed. Rio de Janeiro: Elsevier, 2015.

VILELA RAG. Desafios da vigilância e da prevenção dos acidentes do trabalho. São Paulo: LTR; 2003.

ZAMPIER, M. A.; STEFANO, S. R. Estresse nas empresas de grande porte da região de Guarapuava. Revista de Administração Nobel, v. 1, n. 3, p. 11-20. 2004.

ZANETIC, A. A questão da segurança privada: estudo do marco regulatório dos serviços particulares de segurança, 2005. 208f. Dissertação (Mestrado em Ciência Política). Departamento de Ciência. Política Universidade de São Paulo, 2005. 